\title{
A cost-effectiveness analysis of endoscopic eradication therapy (EET) for management of dysplasia arising in patients with Barrett's esophagus in the United Kingdom
}

V. Pollit, D. Graham, C Leonard, A. Filby, J. McMaster, S.J. Mealing, L.B Lovat \& R.J Haidry

To cite this article: V. Pollit, D. Graham, C Leonard, A. Filby, J. McMaster, S.J. Mealing, L.B Lovat \& R.J Haidry (2018): A cost-effectiveness analysis of endoscopic eradication therapy (EET) for management of dysplasia arising in patients with Barrett's esophagus in the United Kingdom, Current Medical Research and Opinion, DOI: 10.1080/03007995.2018.1552407

To link to this article: https://doi.org/10.1080/03007995.2018.1552407

Accepted author version posted online: 27

Nov 2018.

Submit your article to this journal $\sqsubset$

山 Article views: 5

View Crossmark data $₫$ 
A cost-effectiveness analysis of endoscopic eradication therapy (EET) for management of dysplasia arising in patients with Barrett's esophagus in the United Kingdom

V. Pollit ${ }^{4}$, D. Graham ${ }^{1,2}$, C Leonard ${ }^{3}$, A. Filby ${ }^{4}$, J. McMaster ${ }^{4}$, S.J. Mealing ${ }^{4}$, L.B Lovat ${ }^{1,2}$, R.J Haidry ${ }^{1,2}$

${ }^{1}$ Department of Gastroenterology, University College London Hospital, United Kingdom ${ }^{2}$ Division of Surgery and Science, University College London Hospital, United Kingdom

${ }^{3}$ Medtronic UK Ltd

${ }^{4}$ York Health Economics Consortium, York, United Kingdom

Corresponding author:

Vicki Pollit

York Health Economics Consortium,

Enterprise House, Innovation Way,

University of York,

Heslington, York, YO10 5NQ

Email: vicki.pollit@york.ac.uk 


\begin{abstract}
Background and Aims: Endoscopic eradication therapy (EET) is the first line approach for treating Barrett's Esophagus (BE) related neoplasia globally. The British Society of Gastroenterology (BSG) recommend EET with combined endoscopic resection (ER) for visible dysplasia followed by endoscopic ablation in patients with both low and high grade dysplasia (LGD and HGD). The aim of this study is to perform a cost-effectiveness analysis for EET for treatment of all grades of dysplasia in BE patients.
\end{abstract}

Methods: A Markov cohort model with a lifetime time horizon was used to undertake a cost effectiveness analysis. A hypothetical cohort of United Kingdom (UK) patients diagnosed with BE entered the model. Patients in the treatment arm with LGD and HGD received EET and patients with non-dysplastic BE (NDBE) received endoscopic surveillance only. In the comparator arm, patients with LGD, HGD and NDBE received endoscopic surveillance only. A UK National Health Service (NHS) perspective was adopted and the incremental cost effectiveness ratio (ICER) was calculated. Sensitivity analysis was conducted on key input parameters.

Results: EET for patients with LGD and HGD arising in BE is cost-effective compared to endoscopic surveillance alone (lifetime ICER $£ 3,006$ per QALY gained). The results show that as the time horizon increases, the treatment becomes more cost-effective. The five year financial impact to the UK NHS of introducing EET is $£ 7.1 \mathrm{~m}$.

Conclusions: EET for patients with low and high grade BE dysplasia, following updated guidelines from the BSG has been shown to be cost-effective for patients with BE in the UK.

Keywords: Barrett's Esophagus, Esophageal Cancer, Radiofrequency Ablation, Endoscopic Resection, Cost-effectiveness 


\section{Introduction}

Barrett's Esophagus (BE) is a premalignant condition which arises when the normal squamous esophageal mucosa is replaced by metaplastic columnar epithelium that predisposes to neoplastic progression [1]. Patients with chronic gastro-esophageal reflux disease are predisposed to $\mathrm{BE}$ and is found in up to $15 \%$ of people [2] undergoing upper gastrointestinal (UGI) endoscopy, estimated to be around 18,600 people per year $[3,4]$. BE may progress to invasive esophageal adenocarcinoma (EAC) through low-grade (LGD) and high-grade (HGD) dysplasia [5]. Current estimates range at an annual progression rate of $0.12-0.5 \%$ [5-7]. However once LGD and HGD are pathologically confirmed then the risk of cancer progression is significant enough that all worldwide societies recommend early intervention with endoscopic eradication therapy (EET) to prevent cancer developing [1, 8, 9]. The prognosis from EAC remains very poor indeed with a 5 year survival of less than $15 \%$ in the UK [10] and therefore this approach is attractive.

The reported risk of neoplastic progression from LGD varies significantly from $0.6 \%$ to $13.4 \%$ per patient year $[7,11-13]$. Whereas the risk of progression from HGD is reported from 7 to $19 \%$ [14-16]. The variation in reported risk of progression is likely to be due to misclassification between different BE grades during pathology reporting [13].

Current management options for BE are dependent on the degrees of dysplasia: for nondysplastic BE (NDBE), an initial endoscopy should be performed, followed by endoscopic surveillance at an interval of approximately three to five years depending on the length of BE [17]. For patients with LGD confirmed on two occasions by specialist pathologists then EET can be offered. The management of HGD or intramucosal cancer (IMC) with no submucosal invasion is EET, based on several high quality studies and most international guidelines $[4,9$, 18-20]. 
In 2010, NICE recommended using EET for patients with HGD with endoscopic mucosal resection (EMR) prior to ablative therapy [4]. A recent change in the recommendations published by the British Society of Gastroenterology (BSG) in 2017 states that endoscopic ablation, preferably with Radiofrequency Ablation (RFA), should now also be offered to LGD patients with a confirmed diagnosis on two separate occasions $[17,21]$ as studies suggest that surveillance is less effective than RFA in preventing disease progression [22].

Despite evidence and Society recommendation, the National Oesophageal Cancer Audit in 2016 suggests that up to $30 \%$ of UK patients with high grade dysplasia are still undergoing endoscopic surveillance alone as a disease management strategy rather than EET [23].

The potential higher risk of progression to invasive cancer with endoscopic surveillance alone in patients with confirmed dysplasia may result in a greater health burden and cost impact to the NHS not to mention the significant impact on patients' quality of life with the associated mortality and morbidity. The use of a management strategy of EET for all dysplasia (LGD and HGD patients) over that of endoscopic surveillance may have significant economic implications for health authorities nationally.

This study aims to evaluate the cost effectiveness of EET, versus endoscopic surveillance only as a management strategy for patients diagnosed with LGD or HGD in the UK health care model.

\section{Methods}

An economic model framework containing a cost-effectiveness model (CEM) and budget impact model (BIM) was developed in Microsoft Excel® (Microsoft Corporation, Redmond, WA). The CEM was constructed from the perspective of the United Kingdom National 
Health Service (NHS) and Personal Social Services (PSS) using a hypothetical cohort of patients diagnosed with BE. A lifetime time horizon and annual discount rates of $3.5 \%$ were applied to costs and benefits, as recommended by the NICE reference case [24]. The CEM used an annual cycle length, with a cohort of patients (mean age 62 based on average age of diagnosis within the UK NHS $[25,26])$ entering the model. Patient level benefits in the CEM were quantified using Quality Adjusted Life Years (QALYs), with the key output being an Incremental Cost-Effectiveness Ratio (ICER).

Additional parameters were included into the CEM in order to estimate the financial impact associated with using EET in LGD/HGD patients. The BIM used a maximum time horizon of five years and recorded the cumulative number of procedures as well as the total costs in each of the two treatment arms annually. Including a BIM into the economic framework provides results that are more relevant to hospitals and clinicians.

\subsection{Overview of cost-effectiveness model structure}

The structure of the state transition cohort model utilised is shown in Figures 1a and 1b. At time $t=0$, patients who do not receive EET enter the model in one of three health states: NDBE, LGD or HGD. Thereafter, individuals either remain in their previous health state, move between health states (including progression to EAC) or die based on a series of transition probabilities. All patients who transition to the EAC state undergo surgery with esophagectomy, from which a small proportion will die or are cured [23].

In the treatment arm, patients with either confirmed LGD or HGD are initially managed by EET (EMR being used in a proportion of patients prior to RFA as per most recent published studies $[19,27])$, with success defined on the basis of dysplasia eradication (yes/no). Patients were deemed to have had successful disease clearance post EET after 2 consecutive negative endoscopies where biopsies acquired from the neo-oesophagogastric 
junction (OGJ) and the previous BE segment with Seattle protocol sampling showed no residual neoplasia or intestinal metaplasia. Individuals with NDBE received surveillance only regardless of which arm of the model they are in (treatment or comparator). Allocation across each of the health states is made in a similar manner in both arms of the model following the use of EET, with transition through the health states being at an identical rate to that used in the comparator arm. Individuals are considered 'new' to either LGD or HGD if they were not there in the previous cycle. Death is again possible from all health states.

\subsection{Population and treatment efficacy estimates}

A targeted literature search was undertaken on published economic evaluations of RFA, a key component of the EET strategy, to identify relevant studies which might contain inputs to populate the model. Expert opinion was used to populate inputs where published literature was not identified.

The proportion of patients entering the model in each of the health states in the comparator arm was taken from a UK Health Technology Assessment (HTA) report commissioned by the National Institute for Health and Care Excellence (NICE, Table 1).

Shaheen et al [28] reported randomised control trial data on the treatment efficacy of RFA for both HGD and LGD. These estimates were used in the model for HGD (Table 1), however, more recent data was available from Small et al. [29] on the effectiveness of RFA for LGD specifically and so these were used in the base case analysis (Table 1). The impact of using the older estimates, such as those found in the SURF trial [30], were explored in a sensitivity analysis.

Three studies reporting natural history transition probabilities of BE were identified, all reporting similar inputs $[15,28,31]$. Das et al. [31] had some missing data necessary to populate the model and so was not used in the model. As Inadomi et al. [15] was the most 
up-to-date and adjusted rates to fit overall cancer incidence statistics, this was used as the model base case (Table 1). The use of the other two data sources were explored in sensitivity analyses.

\subsection{Costs and resource use}

Only direct health care resource use was included in the analysis (CEM or BIM). Unit costs for medical treatment were derived from the most recent version of appropriate UK databases at the time of model parameterisation $(2017)[32,33]$. Drug costs for proton pump inhibitors (PPIs; omeprazole, lansoprazole, rabeprazole, pantoprazole and esomeprazole), used for acid suppression during and after the treatment phase, and $\mathrm{H} 2$ antagonist drugs were sourced from the British National Formulary Evidence [34]. The drug dosage for PPIs was doubled for patients undergoing endoscopic treatment, based on clinical expert advice. Drug costs were applied for 12 months following EET. Resource use was taken from a range of sources, including expert opinion from clinicians. The same cost and resource use inputs as used in the cost-effectiveness analysis were used in all budget impact calculations.

A summary of costs and resource use assumptions used in the model is provided in Table 2.

\subsection{Health Related Quality of Life (HRQoL)}

Health state preference weights (utilities) were derived from the published literature (Table 3). The utility for an individual cured from BE post esophagectomy was calculated using data from Inadomi et al [15].

To calculate estimates for health states, disutilities reported in a recent UK clinical guideline developed by NICE [32] were subtracted from the UK age and gender adjusted EuroQol five dimension (EQ-5D) population norms for the age group modelled [35]. This differs to that calculated in the literature in which disutilities were subtracted from a baseline 
utility score of 1 (perfect health) for those without BE. However, it is unrealistic that patients without BE will have perfect health.

Disutilities were also applied following particular events (stricture, surgery for perforation, RFA or EMR and esophagectomy). The periods of time over which these decrements were applied are: stricture - one week, EMR, RFA or perforation surgery - two weeks, esophagectomy - nine months.

A summary of all HRQoL related parameters used in the model is provided in Table 3.

\subsection{Adverse events and mortality}

The rates of stricture during a RFA procedure was taken from a recently published study [19]. No evidence for the rate of perforations during a RFA procedure was identified and so we used expert opinion to inform the base case model parameterisation (Table 3). The absolute mortality risk associated with an esophagetomy was taken from a National OesophagoGastric Cancer Audit [23] and the age and gender adjusted all-cause mortality data was sourced form UK life tables [36].

\subsection{Additional parameters used to inform the BIM}

The UK population, correct at the time of model construction, was taken from UK government statistics [37] and the overall incidence of BE from a recently published study by Masclee et al. [38].

\subsection{Uncertainty analyses}

In addition to exploring the implications of using alternative data sources for key model parameters, Univariate sensitivity analyses were conducted on key model inputs in order to observe the impact on results when one input is varied. Threshold analyses were also 
undertaken for key clinical parameters in order to quantify the impact of these parameters on the cost-effectiveness results.

Probabilistic sensitivity analysis (PSA) was also undertaken to examine the impact on results when all input parameters in the model are varied at the same time. A probability distribution was assigned to each parameter. The model randomly draws a number from each parameters distribution, generating a unique result for each section of the model. The model is run for many iterations and, for each iteration, a result is generated.

\section{Results}

\subsection{Cost-effectiveness analysis}

Over the course of a BE neoplasia patient's lifetime, compared to surveillance only, treatment with EET offered an additional 0.17 QALYs but at a per-patient cost of $£ 502$. The ICER is therefore $£ 3,006$ per QALY gained (Table 4). The lifetime cost of EET $(+£ 3,667)$ is almost completely offset by reductions in the cost of treatment for LGD and HGD (-£1,463 and $£ 2,008$ respectively, Table 4).

In the probabilistic sensitivity analysis, the ICER was below a cost-effectiveness threshold of $£ 20,000$ per QALY gained in $74 \%$ of simulations, with $79 \%$ of simulations generating ICERs below $£ 30,000$ per QALY gained (using a threshold of $£ 30,000$ (Figure

2)). The use of EET in addition to conventional screening was cost-saving in $40 \%$ of probabilistic analyses.

\subsection{Budget impact analysis}

Combining the overall population of the UK and the published annual incidence of Barrett's esophagus results in an estimated 17,955 incidence cases per year. Among these patients, at all years assessed, the use of EET resulted in substantive reductions in predicted numbers of 
both surveillance procedures and esophagectomies (Table 5). Over a five year time frame, the cumulative cost of introducing EET into the UK health care system is approximately $£ 7.1$ million (Table 5).

\subsection{Sensitivity Analysis}

One-way sensitivity analysis were conducted on all key variables within the model, with the model being generally very robust to changes in all parameters. The results from key structural uncertainty analyses are presented in Table 6. The model was also robust to the use of alternative data sources to inform LGD cure rates and the natural history of BE with all ICERs generated being below (or only very marginally above) £20,000 per QALY gained. Alterations to the starting distribution across the health states also only had a modest impact on the ICER, with EET being the dominant strategy in HGD patients (increased benefits at lower cost) and having an ICER of approximately £15,438 per QALY gained in LGD patients (Table 6).

Deterministic threshold analyses around key parameters are presented in Figure 3. The model was sensitive to changes in the scaling factor applied to the NDBE transition rate, with a reduction in this parameter resulting in an increase in progression out of this health state. The ICER increases beyond $£ 20,000$ per QALY gained if the transition rate is $25 \%$ higher (i.e. the scaling factor is approximately 0.75 ). The model was also very sensitive to changes in the time horizon used in the analysis, with ICERs being below $£ 20,000$ per QALY gained after approximately four years. The model conclusions were robust to changes in the dysplasia eradication rates associated with EET in HGD or LGD patients and no meaningful parameter values generated ICERs in excess of $£ 20,000$ per QALY gained. 


\section{Discussion}

The aim of this study was to evaluate the cost effectiveness of EET, which in the majority of patients uses a combination of EMR for visible lesions, followed with sequential RFA treatments and finally concluding with endoscopic surveillance after successful endoscopic eradication, versus endoscopic surveillance only as a management strategy for BE patients diagnosed with LGD or HGD in the UK. The study aimed to reflect the updated BSG recommendations which recommend that endoscopic ablation, preferably with RFA, should now also be offered to LGD patients with a confirmed diagnosis, in addition to HGD patients [21].

The model estimates that EET for Barrett's esophagus patients with dysplasia (both HGD and LGD) in the UK is cost-effective when compared to providing surveillance only. The 'per patient' results show that with a lifetime time horizon, although the total costs are greater in the treatment arm (EET), this is offset by a greater number of total QALYs, giving an ICER of $£ 3,006$ per QALY gained. Furthermore, over a five-year time frame, the cumulative cost of introducing EET into the UK health care system is approximately $£ 7.1$ million which is significant within the context of the current climate of limited and rationed resources for health care. Both cost effectiveness and budget impact results may be conservative if true cost of care preceding and following procedures such as esophagectomy is higher than what is captured within the NHS reference cost.

The costs relating to EET include the cost of EMR for visible lesions, sequential sessions of RFA, adverse events as a result of EET such as stricture formation requiring dilation, and additional drugs taken as a result of RFA. The results show that in the treatment arm there are much lower costs of LGD, HGD and EAC. This is due to patients with LGD and HGD receiving treatment (EET) and therefore returning to the NDBE health state. When patients are in this (NDBE) health state they incur lower costs because, rather than incurring 
treatment costs, they only require surveillance once every 2-5 years. In contrast, within the comparator arm, patients are progressing more quickly, therefore incurring lower quality of life and higher costs.

At the cost-effectiveness threshold used by NICE in their decision-making process (£20,000 per QALY gained), there was a 74\% chance that EET was good value for money, with EET being cost-saving to the UK NHS in approximately $40 \%$ of all probabilistic simulations. The model was robust to alterations to all parameters except the rate at which patients remain in the NDBE health state, with cost-effectiveness being achieved after approximately three years. The rate at which individuals remain in the NDBE health state have to be around $50 \%$ for the ICER to exceed $£ 30,000$ per QALY gained. The base case value is $96.4 \%$.

Continual advances in minimally invasive endoscopic therapy, especially with advanced imaging to guide EMR followed by RFA, should translate into higher rates of disease eradication with an optimised safety profile for these patients making this preventative strategy more patient and cost friendly.

From a budget impact perspective, the use of EET resulted in a $42 \%$ reduction in the number of esophagectomies and a $49 \%$ reduction in the number of surveillance procedures. The latter corresponds to 27,100 fewer procedures undertaken over a five year period which will have a notable impact on service provision within the UK NHS. The estimated five year financial impact to the UK NHS of using EET in BE patients is $£ 7.1$ million.

The results of this study align with the previous literature which has shown RFA to be cost effective for LGD and HGD separately [22, 25, 39]. Although the previous analysis of RFA for only HGD patients resulted in a marginally lower ICER $(£ 1,272)$ [39], the current analysis highlights that use of RFA for both LGD and HGD patients remains significantly cost-effective (ICER: £3,006). Although, NICE clinical guidelines reported ICERs far in 
excess of the current results $(£ 24,829$ [3]). The value in the NICE clinical guideline was generated based on information correct as of 2010 and can therefore be viewed as an outlier since this document is scheduled for an update early in 2018.

A recently published paper by Esteban et al (2016) [40] assessed cost-effectiveness of EET for BE patients with high or low grade dysplasia in Spain. The results of this Spanish model align very closely with the overarching results from our model and as such strengthen confidence in our primary conclusion, namely that EET is a cost-effective use of UK NHS funds in both patients with LGD and HGD. This finding should help inform future national policy and local commissioning decisions regarding affordability and patient access

Many patients are still receiving surveillance only in the UK [17], with up to a third of UK patients with HGD undergoing surveillance for reasons that are not transparent. Without EET, there are potentially more patients' with LGD, HGD and IMC that may progress to invasive cancer as patients progress between the various health states. As patients with dysplasia progress to cancer and are offered surgery without EET, this results in more patients being 'cured' after esophagectomy. This also results in a small proportion of patients dying from surgery but more significant numbers with significant post-operative morbidity with a prolonged lower quality of life after surgery (compared with a person who does not have BE) [41, 42]. Patients with LGD who have been managed with surveillance alone for a long time could progress to HGD at any point and are potentially at "high risk" as evidenced by recent randomised controlled trials (RCTs) $[20,22,30]$. Through managing these patients with EET, commissioners could avoid the potentially high costs associated with progression to cancer.

As with any economic model, there are a number of limitations to the current study that should be noted. A number of inputs used in the model relied on expert opinion as evidence based literature was not available. However, these inputs were tested in the 
sensitivity analysis and did not impact on overall conclusions from the analysis (EET is a cost-effective treatment). The parameter with the highest degree of uncertainty was the natural history transition probabilities of BE. Inputs from alternative sources $[15,28]$ were tested in the one-way sensitivity analysis and produced ICERs below, or only very marginally above the UK cost-effectiveness threshold (max value: $£ 20,057$ per QALY gained). The model does not include the possibility of dysplasia recurrence following successful treatment. However, evidence suggests that the rate of recurrence is low [43]. Therefore, it is not believed that including the recurrence of dysplasia within the model would substantially alter the results. Further, the model does not factor in false negatives and assumes that all patients receive the correct histological diagnosis prior to receiving any treatment. We know that pathological consensus for LGD for example can often be problematic with low interobserver agreement even with expert pathologists $[1,13,44]$. However, this may not be the case in the real world.

\section{Conclusions}

This study demonstrates that, following recently updated guidelines from the BSG, the use of EET for the management of BE patients with all types of dysplasia is cost effective in the UK population. The results of this study provide justification for NHS healthcare providers to follow the updated BSG guidelines and evolve treatment from surveillance alone to EET for patients with a confirmed LGD diagnosis. 


\section{Transparency}

\section{Funding}

This work was funded by Medtronic UK Ltd.

\section{Declaration of financial/other relationships}

C. Leonard disclosed that she is a full time employee at Medtronic UK Ltd. R. Haidry disclosed that he has received grants to support research from Medtronic UK Ltd, Cook Endoscopy and Fractyl Ltd. The authors and CMRO peer reviewers have no other relevant financial or other relationships to disclose.

\section{Contribution statement}

Vicki Pollit: The construction and technical validation of the economic model and writing of the manuscript. David Graham: The clinical review of the manuscript. Catherine Leonard: The conception and design of the economic model, the validation of the economic model and the editorial of the manuscript. Alexandra Filby: The conception and design of the economic model, construction of the economic model and technical review of the manuscript. Jessica McMaster: The construction of the economic model and writing of the manuseript. Stuart J. Mealing: The construction and technical validation of the economic model as well as editorial control of the manuscript. L.B Lovat: The clinical review of the manuscript. Rehan Haidry: The clinical validation of the economic model as well as clinical editorial control of the manuscript.

\section{Acknowledgements}

None reported. 


\section{References}

1. Fitzgerald, R.C., et al., British Society of Gastroenterology guidelines on the diagnosis and management of Barrett's oesophagus. Gut, 2014. 63(1): p. 7-42.

2. Johansson, J., et al., Prevalence of precancerous and other metaplasia in the distal oesophagus and gastro-oesophageal junction. Scand J Gastroenterol, 2005. 40(8): p. 893-902.

3. National Institute for Health and Care Excellence, Epithelial radiofrequency ablation for Barrett's oesophagus. Interventional procedures guidance [IPG344]. 2010, NICE: London.

4. National Institute for Health and Care Excellence, Barrett's oesophagus: ablative therapy. Clinical guideline [CG106]. 2010, NICE: London.

5. Gatenby, P., et al., Lifetime risk of esophageal adenocarcinoma in patients with Barrett's esophagus. World J Gastroenterol, 2014. 20(28): p. 9611-7.

6. Bhat, S., et al., Risk of malignant progression in Barrett's esophagus patients: results from a large population-based study. J Natl Cancer Inst, 2011. 103(13): p. 1049-57.

7. Hvid-Jensen, F., et al., Incidence of adenocarcinoma among patients with Barrett's esophagus. N Engl J Med, 2011. 365(15): p. 1375-83.

8. Weusten, B., et al., Endoscopic management of Barrett's esophagus: European Society of Gastrointestinal Endoscopy (ESGE) Position Statement. Endoscopy, 2017. 49(2): p. 191-198.

9. Shaheen, N.J., et al., ACG Clinical Guideline: Diagnosis and Management of Barrett's Esophagus. Am J Gastroenterol, 2016. 111(1): p. 30-50; quiz 51.

10. Cancer Research UK. [cited 2018 January]; Available from: http://www.cancerresearchuk.org/health-professional/cancer-statistics/statistics-bycancer-type/oesophageal-cancer?_ga=2.109495173.1262586708.1517233566932884114.1509353695.

11. Curvers, W.L., et al., Low-grade dysplasia in Barrett's esophagus: overdiagnosed and underestimated. Am J Gastroenterol, 2010. 105(7): p. 1523-30.

12. de Jonge, P.J., et al., Risk of malignant progression in patients with Barrett's oesophagus: a Dutch nationwide cohort study. Gut, 2010. 59(8): p. 1030-6. 
13. Duits, L.C., et al., Barrett's oesophagus patients with low-grade dysplasia can be accurately risk-stratified after histological review by an expert pathology panel. Gut, 2015. 64(5): p. 700-6.

14. Sharma, P., Clinical practice. Barrett's esophagus. N Engl J Med, 2009. 361(26): p. 2548-56.

15. Inadomi, J.M., et al., A cost-utility analysis of ablative therapy for Barrett's esophagus. Gastroenterology, 2009. 136(7): p. 2101-2114 e1-6.

16. Rastogi, A., et al., Incidence of esophageal adenocarcinoma in patients with Barrett's esophagus and high-grade dysplasia: a meta-analysis. Gastrointest Endosc, 2008. 67(3): p. 394-8.

17. di Pietro, M., R.C. Fitzgerald, and B.S.G.B.s.g.w. group, Revised British Society of Gastroenterology recommendation on the diagnosis and management of Barrett's oesophagus with low-grade dysplasia. Gut, 2017.

18. Phoa, K.N., et al., Multimodality endoscopic eradication for neoplastic Barrett oesophagus: results of an European multicentre study (EURO-II). Gut, 2016. 65(4): p. 555-62.

19. Haidry, R.J., et al., Radiofrequency ablation and endoscopic mucosal resection for dysplastic barrett's esophagus and early esophageal adenocarcinoma: outcomes of the UK National Halo RFA Registry. Gastroenterology, 2013. 145(1): p. 87-95.

20. Shaheen, N.J., et al., Radiofrequency ablation in Barrett's esophagus with dysplasia. N Engl J Med, 2009. 360(22): p. 2277-88.

21. Leggett, C.L., E.C. Gorospe, and K.K. Wang, Endoscopic therapy for Barrett's esophagus and early esophageal adenocarcinoma. Gastroenterol Clin North Am, 2013. 42(1): p. 175-85.

22. Phoa, K.N., et al., The cost-effectiveness of radiofrequency ablation for Barrett's esophagus with low-grade dysplasia: results from a randomized controlled trial (SURF trial). Gastrointest Endosc, 2017. 86(1): p. 120-129 e2.

23. Varagunam, M.B., C. Cromwell, D. et al., , National Oesophago-Gastric Cancer Audit. 2017, NHS,.

24. National Institute for Health and Care Excellence, Developing NICE guidelines: the manual. 2014.

25. Hur, C., et al., The cost effectiveness of radiofrequency ablation for Barrett's esophagus. Gastroenterology, 2012. 143(3): p. 567-575. 
26. National Health Service. NHS Choices. Heartburn and gastro-oesophageal reflux disease - Complications. 2016 [cited 2017 20th November]; Available from: https://www.nhs.uk/conditions/heartburn-and-acid-reflux/\#complications-ofgord.

27. Desai, M., et al., Efficacy and safety outcomes of multimodal endoscopic eradication therapy in Barrett's esophagus-related neoplasia: a systematic review and pooled analysis. Gastrointest Endosc, 2017. 85(3): p. 482-495 e4.

28. Shaheen, N.J., et al., Durability of radiofrequency ablation in Barrett's esophagus with dysplasia. Gastroenterology, 2011. 141(2): p. 460-8.

29. Small, A.J., et al., Radiofrequency Ablation Is Associated With Decreased Neoplastic Progression in Patients With Barrett's Esophagus and Confirmed Low-Grade Dysplasia. Gastroenterology, 2015. 149(3): p. 567-76 e3; quiz e13-4.

30. Phoa, K.N., et al., Radiofrequency ablation vs endoscopic surveillance for patients with Barrett esophagus and low-grade dysplasia: a randomized clinical trial. JAMA, 2014. 311(12): p. 1209-17.

31. Das, A., et al., An economic analysis of endoscopic ablative therapy for management of nondysplastic Barrett's esophagus. Endoscopy, 2009.41(5): p. 400-8.

32. National Institute for Health and Care Excellence, Clinical Guideline 106. Appendix 6: Cost effectiveness analysis for Barrett's oesophagus. 2010.

33. Department of Health, NHS Reference cost 2015-2016. 2016.

34. Joint Formulary Commitee. British National Formulary. [cited 2017 4th October]; Available from: https://www.bnf.org/.

35. Kind, P.H., Geoffrey Macran, Susan, UK population norms for EQ-5D. 1999, University of York: York.

36. Office of National Statistics, National Life Tables, United Kingdom: 2012-2014. 2015.

37. Office of National Statistics, UK Population estimates 2017.

38. Masclee, G.C., P; Wilde, M; Kuipers, E; Sturkenboom,M, The incidence of Barrett's oesophagus and oesophageal adenocarcinoma in the United Kingdom and the Netherlands is levelling off. Alimentary Pharmacology and Therapeutics, 2014. 39(11): p. 1321-1330.

39. Filby, A., et al., Cost-effectiveness analysis of endoscopic eradication therapy for treatment of high-grade dysplasia in Barrett's esophagus. J Comp Eff Res, 2017. 6(5): p. $425-436$. 
40. Esteban, J., Gonzalez, P., Gornals, JB., Collados, C., Alverez, M., Perez-Mitru,A., Serip,S.,, Cost-effectiveness of endoscopic treatment with radiofrequency ablation for patients with Barrett's esophagus and high or low grade dysplasia in Spain. Value in Health 2016. 19(7): p. A512-A513.

41. Soriano, T.T., G.D. Eslick, and T. Vanniasinkam, Long-Term Nutritional Outcome and Health Related Quality of Life of Patients Following Esophageal Cancer Surgery: A Meta-Analysis. Nutr Cancer, 2018. 70(2): p. 192-203.

42. Kauppila, J.H., et al., Meta-analysis of health-related quality of life after minimally invasive versus open oesophagectomy for oesophageal cancer. Br J Surg, 2017. 104(9): p. 1131-1140.

43. Fujii-Lau, L.L., et al., Recurrence of intestinal metaplasia and early neoplasia after endoscopic eradication therapy for Barrett's esophagus: a systematic review and metaanalysis. Endoscopy International Open, 2017. 5(6): p. E430-E449.

44. Wani, S., et al., Diagnosis and Management of Low-Grade Dysplasia in Barrett's Esophagus: Expert Review From the Clinical Practice Updates Committee of the American Gastroenterological Association. Gastroenterology, 2016. 151(5): p. 822835.

45. Garside, R., et al., Surveillance of Barrett's oesophagus: exploring the uncertainty through systematic review, expert workshop and economic modelling. Health Technol Assess, 2006. 10(8): p. 1-142, iii-iv.

46. Boger, P.C., et al., A UK-bâsed cost-utility analysis of radiofrequency ablation or oesophagectomy for the management of high-grade dysplasia in Barrett's oesophagus. Aliment Pharmacol Ther, 2010. 32(11-12): p. 1332-42. 
TABLES

Table 1: $\quad$ Effectiveness inputs and sources

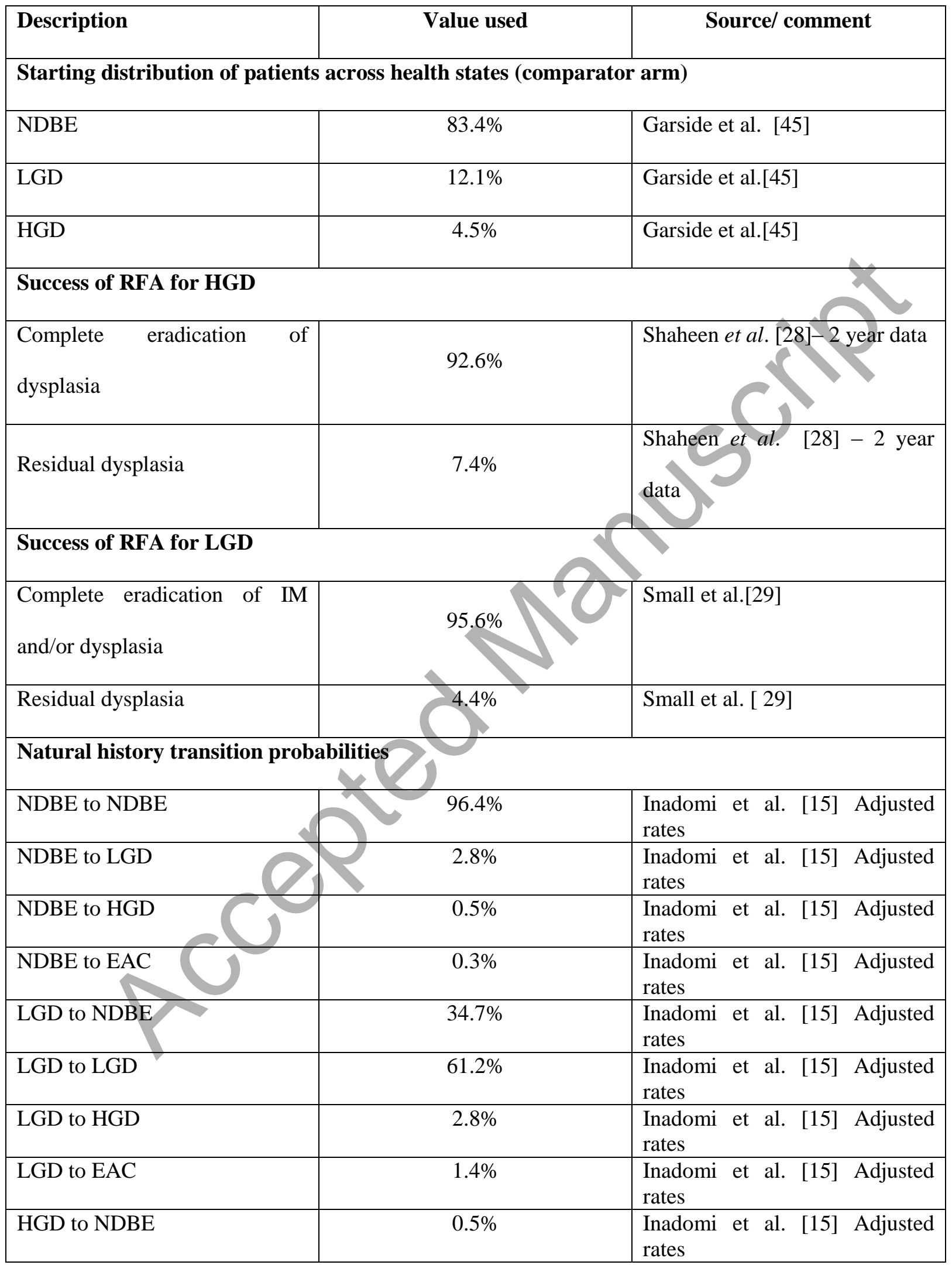




\begin{tabular}{|l|c|l|}
\hline HGD to LGD & $3.9 \%$ & $\begin{array}{l}\text { Inadomi et al. [15] Adjusted } \\
\text { rates }\end{array}$ \\
\hline HGD to HGD & $92.6 \%$ & $\begin{array}{l}\text { Inadomi et al. [15] Adjusted } \\
\text { rates }\end{array}$ \\
\hline HGD to EAC & $3.0 \%$ & $\begin{array}{l}\text { Inadomi et al. [15] Adjusted } \\
\text { rates }\end{array}$ \\
\hline
\end{tabular}

Abbreviations: NDBE: Non-dysplastic Barrett's Esophagus; LGD: Low-grade dysplasia; HGD: High-grade dysplasia; RFA: Radiofrequency Ablation; EAC: Esophageal Adenocarcinoma

Table 2: $\quad$ Cost and Resource use inputs

\begin{tabular}{|c|c|c|c|}
\hline Description & $\begin{array}{l}\text { Unit } \\
\text { cost }\end{array}$ & Source & Notes/ comments \\
\hline \multicolumn{4}{|c|}{ DRG/ HRG Tariff values } \\
\hline RFA & $£ 1,709$ & $\begin{array}{l}\text { NHS Reference } \\
\text { costs [33] }\end{array}$ & $\begin{array}{l}\text { Weighted average of values Major Therapeutic } \\
\text { Endoscopic, Upper or Lower Gastrointestinal Tract } \\
\text { Procedures, } 19 \text { years and over. Elective inpatient. } \\
\text { Mean number of sessions (3) based on published } \\
\text { literature [30] }\end{array}$ \\
\hline EMR & $£ 678$ & & $\begin{array}{l}\text { Weighted average day case values for Major } \\
\text { Therapeutic Endoscopic, Upper or Lower } \\
\text { Gastrointestinal Tract Procedures, } 19 \text { years and over. } \\
\text { Mean number of treatments (1) based on expert } \\
\text { opinion }\end{array}$ \\
\hline Cost of stricture & $£ 4,663$ & $\begin{array}{l}\text { NHS Reference } \\
\text { costs [33] }\end{array}$ & $\begin{array}{l}\text { Based on expert opinion and published literature [32] } \\
\text { assumed to be } 1.3 \text { day case and } 1.3 \text { elective } \\
\text { procedures. Costs for each a weighted average of } \\
\text { relevant reported values for Major Therapeutic } \\
\text { Endoscopic, Upper or Lower Gastrointestinal Tract } \\
\text { Procedures, } 19 \text { years and over }\end{array}$ \\
\hline
\end{tabular}




\begin{tabular}{|c|c|c|c|}
\hline $\begin{array}{l}\text { Cost } \\
\text { perforation }\end{array}$ & $£ 7,166$ & $\begin{array}{l}\text { NHS Reference } \\
\text { costs [33] }\end{array}$ & $\begin{array}{l}\text { Weighted average of reported values for Complex, } \\
\text { Esophageal, Stomach or Duodenum Procedures, } 19 \\
\text { years and over, cc score of 2-3. (Elective inpatient } \\
\text { only) }\end{array}$ \\
\hline Esophagectomy & $£ 8,968$ & $\begin{array}{l}\text { NHS Reference } \\
\text { costs [33] }\end{array}$ & $\begin{array}{l}\text { Weighted average of reported values Complex, } \\
\text { Esophageal, Stomach or Duodenum Procedures, } 19 \\
\text { years and over, cc score of } 2-3 \text {. (Elective inpatient). } \\
\text { Cost of six additional days of stay added based on } \\
\text { expert opinion ( } £ 300 \text { per day) }\end{array}$ \\
\hline $\begin{array}{l}\text { Endoscopy/ } \\
\text { biopsy }\end{array}$ & $£ 686$ & $\begin{array}{l}\text { NHS Reference } \\
\text { costs [33] }\end{array}$ & $\begin{array}{l}\text { Weighted average of reported values for Combined } \\
\text { Upper and Lower Gastrointestinal Tract Diagnostic } \\
\text { Endoscopic Procedures with Biopsy, } 19 \text { years and } \\
\text { over. Resource use protocol based on published } \\
\text { literature [1] and expert opinion [NDBE: } 1 \text { every } 3 \\
\text { years, LGD: } 2 \text { per year, HGD: } 3 \text { per year] [29] }\end{array}$ \\
\hline \multicolumn{4}{|c|}{ Drug costs (annual unless otherwise stated) } \\
\hline Omeprazole & $£ 44$ & $\begin{array}{l}\text { British } \\
\text { National } \\
\text { Formulary [34] }\end{array}$ & $\begin{array}{l}\text { Common usage in all three health states (NDBE, } \\
\text { LGD, HGD) based on expert opinion }\end{array}$ \\
\hline Lansoprazole & $£ 46$ & $\begin{array}{l}\text { British } \\
\text { National } \\
\text { Formulary [34] }\end{array}$ & $\begin{array}{l}\text { Common usage in all three health states (NDBE, } \\
\text { LGD, HGD) based on expert opinion }\end{array}$ \\
\hline Rabeprazol & $£ \varepsilon$ & $\begin{array}{l}\text { British } \\
\text { National } \\
\text { Formulary [34] }\end{array}$ & $\begin{array}{l}\text { Common usage in all three health states (NDBE, } \\
\text { LGD, HGD) based on expert opinion }\end{array}$ \\
\hline Pantoprazole & $£ 91$ & $\begin{array}{l}\text { British } \\
\text { National } \\
\text { Formulary [34] }\end{array}$ & $\begin{array}{l}\text { Common usage in all three health states (NDBE, } \\
\text { LGD, HGD) based on expert opinion }\end{array}$ \\
\hline Esomeprazole & $£ 67$ & $\begin{array}{l}\text { British } \\
\text { National } \\
\text { Formulary [34] }\end{array}$ & $\begin{array}{l}\text { Common usage in all three health states (NDBE, } \\
\text { LGD, HGD) based on expert opinion }\end{array}$ \\
\hline Ranitidine & $£ 445$ & $\begin{array}{l}\text { British } \\
\text { National }\end{array}$ & Cost of Ranitidine $\mathrm{H} 2$ antagonist drugs assumed to \\
\hline
\end{tabular}


\begin{tabular}{|l|l|l|l|}
\hline & & Formulary [34] & be required following surgery
\end{tabular}

Abbreviations: RFA: Radiofrequency ablation; EMR: Endoscopic mucosal resection; NDBE: Non-dysplastic

Barrett's Esophagus; LGD: Low-grade dysplasia; HGD: High-grade dysplasia

Table 3: $\quad$ Utility and adverse events inputs

\begin{tabular}{|c|c|c|}
\hline Description & Value used & Source (s) \\
\hline \multicolumn{3}{|l|}{ Fixed utility inputs } \\
\hline Cured (or no BE) & 0.80 & EuroQoL UK population norms \\
\hline NDBE & 0.71 & NICE CG106. Appendix 6[32] \\
\hline LGD & 0.65 & NICE CG106. Appendix 6 [32] \\
\hline HGD & 0.57 & NICE CG106. Appendix 6 [32] \\
\hline EAC & 0.48 & NICE CG106. Appendix 6 [32] \\
\hline Cured-post-esophagectomy & 0.77 & Calculated from Inadomi et al. (2009) [15] \\
\hline \multicolumn{3}{|l|}{ Utility decrements } \\
\hline Stricture & & NICE CG106. Appendix 6 [32] \\
\hline Surgery for perforation & & NICE CG106. Appendix 6 [32] \\
\hline EMR and RFA surgery & 0.06 & Boger et al. (2010) [46] \\
\hline Esophagector & -0.26 & NICE CG106. Appendix 6 [32] \\
\hline \multicolumn{3}{|l|}{ Safety inputs } \\
\hline Stricture in RFA procedure & $9 \%$ & Haidry et al. (2013) [19] \\
\hline $\begin{array}{l}\begin{array}{l}\text { Perforation in } \\
\text { procedure }\end{array} \\
\end{array}$ & $0.01 \%$ & Clinical expert opinion \\
\hline $\begin{array}{ll}\text { Mortality } & \text { from } \\
\text { esophagectomy } & \end{array}$ & $1.9 \%$ & $\begin{array}{l}\text { National Oesophago-Gastric Cancer Audit. } \\
2016[23] \text {. }\end{array}$ \\
\hline All-cause mortality & Time dependant & UK Office for National Statistics (ONS) [36] \\
\hline
\end{tabular}

Abbreviations: BE: Barrett's Esophagus; NDBE: Non-dysplastic Barrett's Esophagus; LGD: Low-grade dysplasia; HGD: High-grade dysplasia; EAC: Esophageal Adenocarcinoma; EMR: Endoscopic mucosal resection; RFA: Radiofrequency ablation 
Table 4: $\quad$ Base case cost-effectiveness model results

\begin{tabular}{|c|c|c|c|}
\hline & EET & Endoscopic surveillance & $\Delta$ \\
\hline Cost of EET & $£ 3,667$ & $£ 0$ & $£ 3,667$ \\
\hline Cost of NDBE & $£ 4,040$ & $£ 3,446$ & $£ 594$ \\
\hline Cost of LGD & $£ 34$ & $£ 1,496$ & $-£ 1,463$ \\
\hline Cost of HGD & $£ 20$ & $£ 2,028$ & $-£ 2,008$ \\
\hline Cost of EAC & $£ 372$ & $£ 660$ & $-£ 288$ \\
\hline Total cost & $£ 8,133$ & $£ 7,630$ & $£ 502$ \\
\hline Total QALYS & $\mathbf{1 0 . 3 3 4}$ & 10.167 & \\
\hline ICER & & $£ 3,006$ per QAI & \\
\hline
\end{tabular}

Abbreviations: EET: Endoscopic Eradication Therapy; NDBE: Non-dysplastic Barrett's Esophagus; LGD: Lowgrade dysplasia; HGD: High-grade dysplasia; EAC: Esophageal Adenocarcinoma; QALY: Quality Adjusted Life Year; ICER: Incremental Cost Effectiveness Ratio

Table 5: $\quad$ Predicted number of events, and number of events from the budget impact analysis (total population $=17,955)$

\begin{tabular}{|l|c|c|c|}
\hline & EET & Endoscopic surveillance & $\Delta$ \\
\hline Time horizon = 1 year & 8,936 & 0 & 8,936 \\
\hline Number of RFA procedures & 725 & 0 & 725 \\
\hline Number of EMR procedures & 4,942 & 11,715 & $-6,773$ \\
\hline Number of surveillance procedures & 21 & 48 & -27 \\
\hline Number of esophagectomies & $£ 19,340,950$ & $£ 8,466,851$ & $£ 10,874,099$ \\
\hline Total cost & 12,126 & 0 & 12,126 \\
\hline Time horizon = 3 years & 926 & 0 & 926 \\
\hline Total number of RFA procedures & 16,313 & 33,654 & $-17,341$ \\
\hline Total number of EMR procedures & 129 & 234 & -105 \\
\hline Total number of surveillance procedures & $£ 33,699,283$ & $£ 25,183,799$ & $£ 8,515,484$ \\
\hline Total number of esophagectomies & 15,496 & 0 & 15,496 \\
\hline Total cost
\end{tabular}




\begin{tabular}{|l|c|c|c|}
\hline Total number of EMR procedures & 1,140 & 0 & 1,140 \\
\hline Total number of surveillance procedures & 27,530 & 54,648 & $-27,118$ \\
\hline Total number of esophagectomies & 239 & 412 & -173 \\
\hline Total cost & $£ 48,289,385$ & $£ 41,190,117$ & $£ 7,099,268$ \\
\hline
\end{tabular}

Abbreviations: EET: Endoscopic Eradication Therapy; EMR: Endoscopic mucosal resection; RFA:

Radiofrequency ablation

Table 6: Key deterministic sensitivity analyses

\begin{tabular}{|c|c|c|c|c|c|}
\hline & \multicolumn{2}{|c|}{ EET } & \multicolumn{2}{|c|}{ Endoscopic surveillance } & ) \\
\hline & Costs & QALYs & Costs & QALYS & ICER \\
\hline Base case & $£ 8,133$ & 10.33 & $£ 7,630$ & 10.17 & $£ 3,006$ \\
\hline \multicolumn{6}{|c|}{ Alternative sources for LGD cure rate } \\
\hline Phoa et al. & $£ 8,140$ & 10.33 & $£ 7,630$ & 10.17 & $£ 3,087$ \\
\hline Shaheen et al. & $£ 8,126$ & 10.34 & $£ 7,630$ & 10.17 & $£ 2,936$ \\
\hline \multicolumn{6}{|c|}{ Alternative sources for Natural history transition values } \\
\hline $\begin{array}{l}\text { Inadomi et al. published } \\
\text { values }\end{array}$ & $£ 10,377$ & 10.33 & & 10.16 & $£ 14,356$ \\
\hline Shaheen et al. & $£ 10,385$ & 10.34 &, 426 & 10.19 & $£ 20,730$ \\
\hline \multicolumn{6}{|l|}{ Alternative starting distribution } \\
\hline $100 \%$ patients LGD & $£ 13,023$ & 10.31 & $£ 9,471$ & 10.08 & $£ 15,438$ \\
\hline $100 \%$ patients HGD & $£ 13,225$ & 10.19 & $£ 21,206$ & 9.22 & Dominant \\
\hline
\end{tabular}

Abbreviations: EET: Endoscopic Eradication Therapy; QALY; Quality Adjusted Life Year; ICER: Incremental

Cost Effectiveness Ratio; LGD: Low-grade dysplasia; HGD: High-grade dysplasia 


\section{Figure Legends}

\section{Figure 1a: Model structure - Treatment arm.}

Recommended surveillance intervals for NDBE are 2-5 years, LGD are 6 months until confirmed on 2 consecutive occasions and then be offered EET, HGD/EAC are no surveillance and EET.

Abbreviations: NDBE, non-dysplastic Barrett's esophagus; LGD, low-grade dysplasia; HGD, high-grade dysplasia; EAC, esophageal adenocarcinoma; EET, endoscopic eradication therapy.

\section{Figure 1b: Model structure - Comparator arm.}

Abbreviations: NDBE, non-dysplastic Barrett's esophagus; LGD, low-grade dysplasia; HGD, high-grade dysplasia; EAC, esophageal adenocarcinoma.

\section{Figure 2: $\quad$ Results of probabilistic sensitivity analysis.}

Abbreviations: QALY, quality adjusted life year; EET, endoscopic eradication therapy.

\section{Figure 3: Key deterministic threshold analyses.}

Abbreviations: ICER, incremental cost effectiveness ratio; NDBE, non-dysplastic Barrett's esophagus; LGD, low-grade dysplasia; HGD, high-grade dysplasia; EET, endoscopic eradication therapy. 
(A)

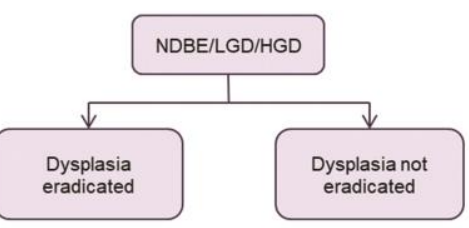

Patients enter Markov model

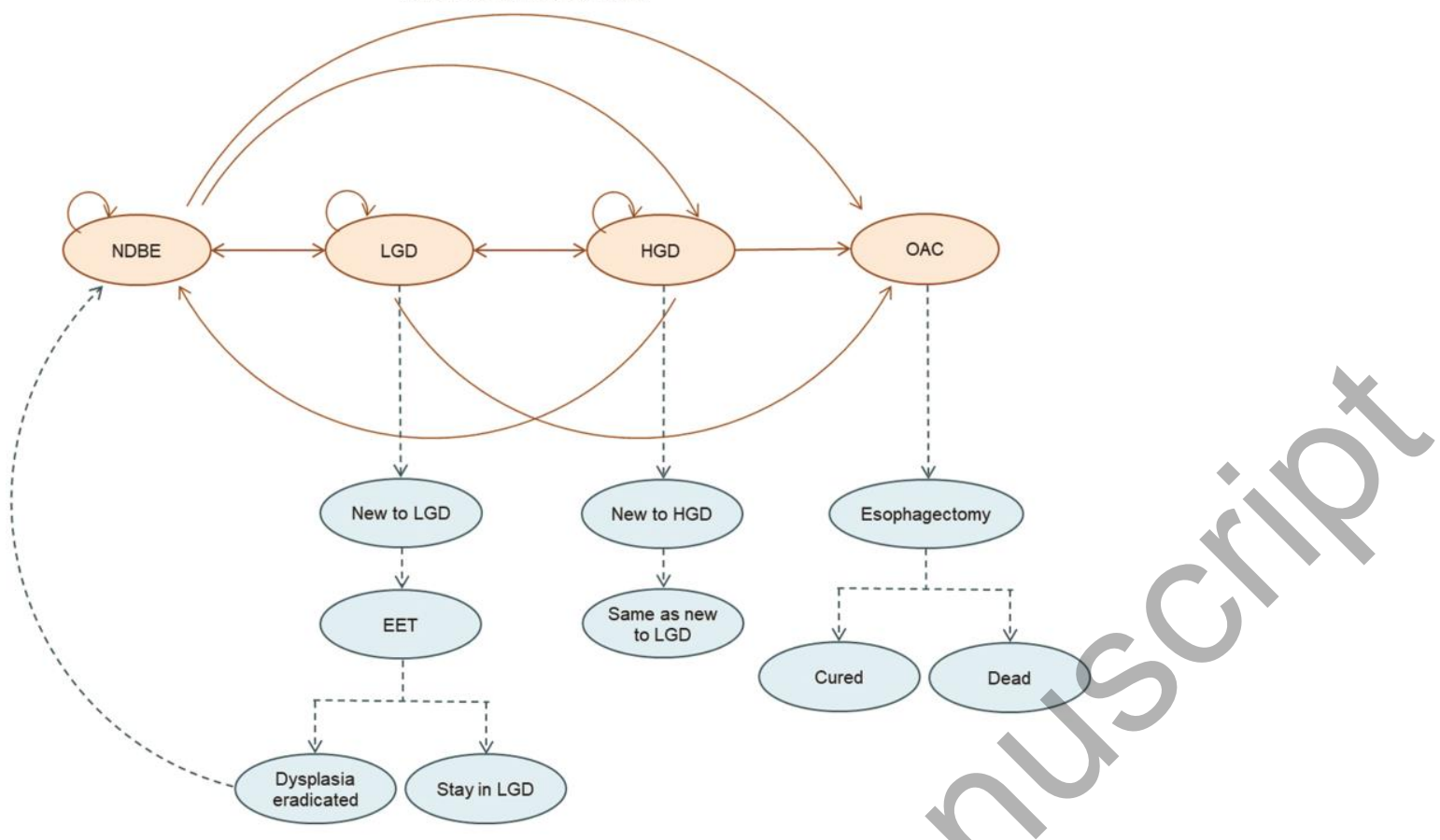

(B)

NDBE/LGD/HGD

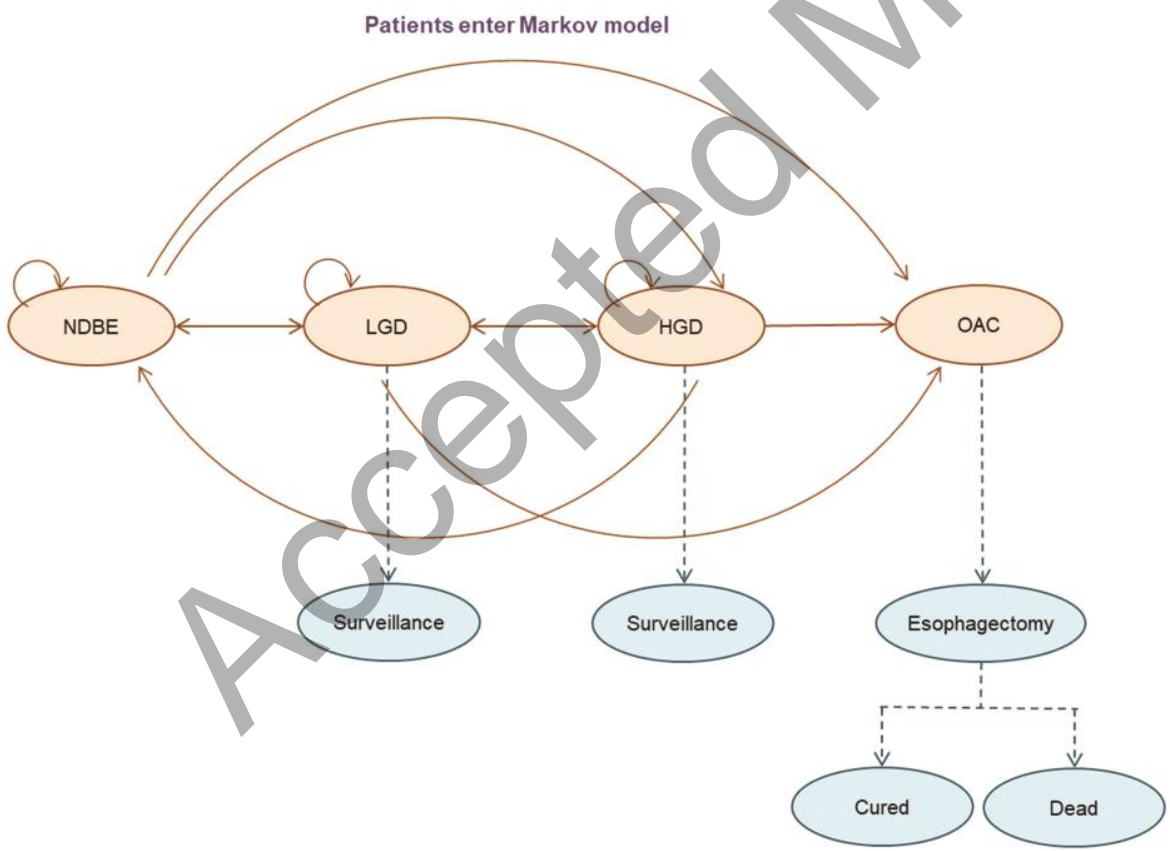




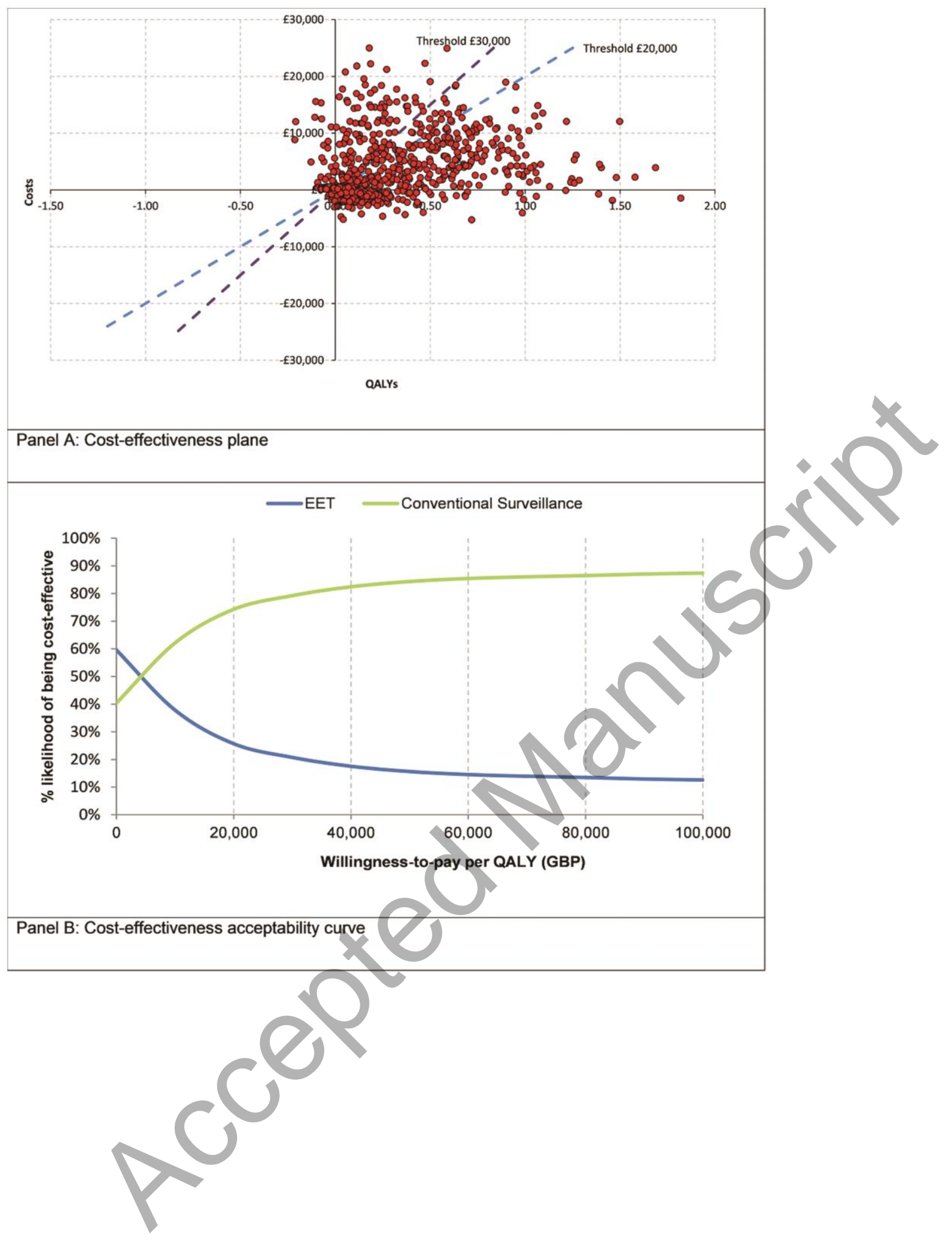




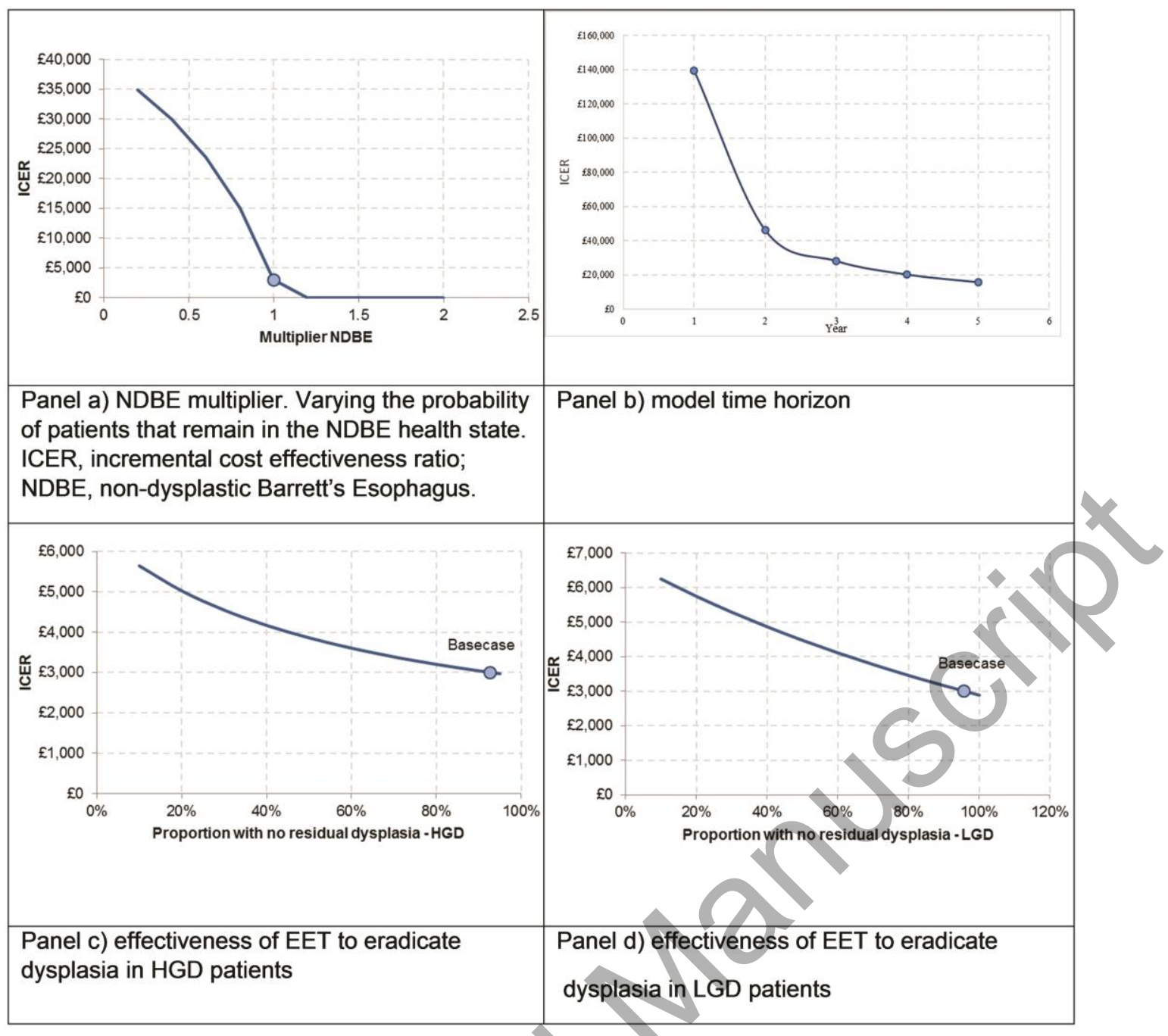

